\title{
Building community capacity and resilience through Emergency Services Cadets
}

\author{
Sally Baisden \\ sally.baisden@pcyc.org.au
}

\begin{abstract}
The Queensland Emergency Services Cadets Program (ESCP) is a unique experiential education program that engages with young people aged from twelve to seventeen years, the majority of whom face the particular challenges of living in rural, remote and urban disadvantaged communities. The ESCP aims to build capacity and resilience in individuals, families and communities by providing young people with opportunities to develop skills, increase confidence, foster greater connection and belonging to community, and provide a sense of purpose through emergency preparedness. This article explores how ESCP positively impacts on cadets' lives by delivering a capacity-building program that teaches disaster response and emergency management skills; allows all participants to enter on an even platform; draws on the cooperation and support of multiple emergency services, local councils, schools, businesses, community resources and dedicated volunteers; and is provided at no cost to participants. By positioning young people as capable and competent, and supporting them to learn and demonstrate their skills and knowledge within their community, the article argues the ESCP delivers specific and tangible developmental outcomes for young people and their communities. Specific outcomes discussed include the empowerment of cadets to become self-determining, the strengthening of the community's collective knowledge and the promotion of a positive image of young people within their community.
\end{abstract}

\section{Introduction}

The PCYC Emergency Services Cadets Program (ESCP) provides an opportunity for young people aged from twelve to seventeen years to engage with their community through a program of experiential learning, volunteerism and mentoring opportunities. Each unit operates out of a host emergency service, and relies on the cooperation and support of multiple emergency services, local councils, schools, businesses, community resources and dedicated volunteers. In June 2016, over 430 Cadets and over 110 volunteer Adult Leaders were engaged in the program across fourteen units, with all expenses funded by the Queensland Government's Queensland Fire and Emergency Services (QFES) at no cost to participants, and with 
all infrastructure and program support delivered by Police Citizens Youth Clubs Queensland (PCYC) (Baisden 2016). Through this article, I explore the positive impacts of the ESCP on the young people who participate, with a focus on the benefits of inclusive practices and how we have observed the ways in which these practices contribute to achieving the outcomes of self-determination, strengthening of collective knowledge and the building of a positive image of young people within the community.

As outlined in the Good Practice Principles for Youth Development Organisations (Seymour 2012), for a strengths-based youth development program to be authentically impactful, it is important that there is a solid understanding of the strengths and capacity of young people and their communities where the program is offered. In order to place context behind strengths, we also need to gain a perspective on the community's potential challenges. For the ESCP, fourteen units are operational throughout Queensland. A total of 246 (57 per cent) of cadets live in rural or remote Queensland; ten units ( 71 per cent) operate in low socio-economic areas; ten units (71 per cent) fall within the lowest quintile of education and occupation rates; and eleven units (79 per cent) are in the top fifty high-needs areas of Queensland (ABS 2011; Baisden 2016). The limitations imposed by distance, low socio-economic status, the lack of a sense of belonging and the lack of availability of services or recreational outlets can be identified in many of the regions the program is operating. Currently, units are located in Biggenden, Bowen, Childers, Cooroora, Gayndah, Hervey Bay, Hughenden, Inglewood, Mackay, Palm Island, Redland City, St Laurence's College (Brisbane), Tara and Wolffdene. The ESCP uses a strengths-based approach that recognises the contextual impact of these challenges on young people's lives while retaining a strong and clear focus on each young person's strengths. In the communities that host an Emergency Services Cadets Unit, I have witnessed an unbridled sense of determination and willingness to invest in young people, which paves the way for the ESCP to have a positive impact on young people and their communities.

\section{Strengths-Based Approach}

The application and assessment process through which young people and adult volunteers must progress as they enter into the ESCP illustrates the benefits that can flow from a focus on strengths. A one-on-one interview takes place between an established ESCP member and the new recruit, with the questions asked focusing on what the applicant believes they will bring to the program by way of skills, knowledge, new ideas and personality attributes. This process has purposefully been designed to provide a basic vetting tool for the intent and commitment of the recruit, as well as a mechanism by which community members who aspire to become adult leaders are able to frame their own assets positively as a toolkit for the benefit of cadets. I have conducted interviews with adult leader and cadet applicants from widely diverse backgrounds and rejoice in the discussions that tease out passionate reasoning and an enthusiastic vision for the program. Further, I find that the brightest moments of the program are those in which seasoned volunteers with little experience interacting with young people conduct these interviews and are at once astounded and inspired by the aspiring cadets. Through this process 
of valuing individuals, and engaging people in new and alternative activities, the ESCP helps to build youth and community capacity.

Volunteers are empowered to think laterally with their skills and qualifications to design innovative learning experiences within the remit of the ESCP. This is valuable to the cadets, as it not only models the flexibility and innovation encapsulated in Seymour's (2012) framework but also provides a unique depth of opportunities that sees no two cadet units exposed to the same program of activities. The process of developing a program of activities can be rejuvenating for a volunteer emergency service unit. By hosting an ESC unit, I have seen how adult members located in Rural Fire stations or State Emergency Service (SES) groups have found new purpose in passing down knowledge and skills, and welcoming young people into their space. Under the mentorship of local emergency services personnel and diverse community members who volunteer as program leaders, young people learn new skills and knowledge, increasing their capacity to contribute to the community's collective strength in new and different ways. Our volunteer base currently consists of adult leaders ranging in age from eighteen to seventy-eight, with diverse backgrounds such as ex-military personnel, librarian, stay-at-home parent, teacher, cartographer, firefighter, police officer, administration clerk, chef, landscaper, retiree and store manager to name a few. I believe that by providing cadets with a broad range of experiences, and exposing them to a diverse array of community members, we help them to develop into well-rounded young adults who are more likely to engage positively in society than their peers, who have little interaction with those outside their familial and school friendship groups.

\section{Inclusivity}

The inclusive practices that underpin the ESCP strongly align to those practices underpinning Seymour's Principle 3: an inclusive ethos. In the ESCP, young people benefit from operating in a safe, supportive environment that is flexible to their needs yet demands that they develop their own flexibility in experiencing and learning to value difference and different ways of thinking and doing things. From a broader perspective, PCYC Queensland and Queensland Fire and Emergency Services both promote inclusivity in their Strategic Plans, which is a powerful precursor to the implementation of the ESCP in such a dynamic youth engagement space (PCYC 2016; QFES 2015). I believe it is a testament to the program that we actively search for the greatest breadth of characters to become volunteers, and that we strive to provide cadets with the biggest array of experiences across all emergency services agencies and in the most diverse places that self-identify as a location to sustain an ESCP Unit (Baisden 2016). As a result, young people who engage in the program anecdotally report instances of being inspired or motivated by the most unlikely of experiences in scenarios that are truly unique, yet somehow in our world of the ESCP seem totally normal.

The ESCP promotes the opportunity for young people to be self-determining by being inclusive, and inviting all cadets to an even platform regardless of background, gender, education, religion, sexuality, family status, employment, ability or disability. It is my belief that the opportunity for a cadet to put on a uniform and receive the same skills, training and mentoring as their peers can be life changing - especially for those who may experience challenges at home, 
school or in other areas of life. As discussed in the Good Practice Principles for Youth Development Organisations, a young person's internal factors, such as drive, flexibility, resilience and confidence, can override the negative impact that external factors such as poor educational outcomes and low socio-economic status can have on young people's lives by reducing the likelihood a young person will engage in negative life-impacting risk-taking behaviours. Facets of the ESCP that encourage self-determination include providing a safe and supportive environment, providing opportunities to make decisions and practise leadership, and encouraging connection to an array of community members and leaders. Through our inclusive practices, and by upholding a strengths-based view of every cadet, we work hard to nurture young people's positive self-image and their self-determination.

\section{Building Resilience}

The model of the ESCP includes all cohorts of the local community as valuable contributors to the next generation of emergency service volunteers, with one of the greatest shared goals being the strengthening of collective knowledge (Baisden 2016). Specifically, the desired outcomes for communities who host a unit are that communities experience an increase in capacity to respond to, and resilience to bounce back from, challenging times through expanding disaster preparedness and response skills within their young members. As a positive soft outcome, I have seen adult volunteer leaders building their own capacity as they embark on their journey supporting cadets. This adult journey of learning benefits young people too, as the adult leaders vicariously learn new skills through supporting cadet training exercises and reinforce their own knowledge through the process of transferring skills to the cadets and fellow adult leaders. In my experience, when the members of a community feel valued, connected, secure and confident, a sense of strength and resilience becomes self-perpetuating.

\section{Conclusion}

The building of a positive image of young people in the eyes of community members in locations of ESCP units is critical to the success of the program. Having buy-in to the value of the outcomes for young people from the local emergency services, schools, local councils, businesses, community service agencies and community members is essential for gaining widespread support and investment in the program. Without a positive image of young people, it is difficult to engage widely across the community. We have, however, seen first hand how the breaking down of barriers and forging of common ground between young people and established organisations have led to great outcomes such as increased volunteerism, an enhanced sense of community and increased instances of emergency service interoperability. The process of opening communication, building rapport, establishing trust, qualifying respect and recognising strengths between young people and community members (both professional and non-professional) is one that takes time, planning and consistent patience. By seeing young people as capable and competent, we not only empower them to become self-determining, we also support them to demonstrate their value to the wider community and we promote a positive image of young people within the community. By striving to include young 
people and adults of all backgrounds, skill levels and abilities, we value the rich diversity of knowledge and experience that individuals bring and the power of strengthening collective skills as an outcome of the process. The Good Practice Principles for Youth Development Organisations (Seymour 2012) advocate that the adoption of inclusive practices leads to more effective and more responsive program delivery within the youth development sector. This ethos has become a cornerstone of the ESCP in our endeavours to develop a sustainable program that is locally owned, organically feeding shared positive outcomes back into the community.

\section{References}

Australian Bureau of Statistics (ABS) 2011. Socio-Economic Indexes for Areas (SEIFA) - Data only, cat. no. 2033.0.55.001. Canberra: ABS, http://www.abs.gov.au/ AUSSTATS/abs@.nsf/DetailsPage/2033.0.55.0012011?OpenDocument.

Baisden S. 2016. Emergency Services Cadets annual report. Brisbane: PCYC

Seymour K. 2012. Good practice principles for youth development organisations, 2nd ed. Brisbane: Key Centre for Ethics, Law, Justice and Governance, Griffith University.

Police Citizens Youth Clubs Queensland (PCYC) 2016. PCYC strategic snapshot. Brisbane: PCYC.

Queensland Fire and Emergency Services (QFES) 2015. Strategic plan 2015-2019, https://www.qfes.qld.gov.au/documents/QFES-Strategic-Plan-2015-2019.pdf. 